\title{
Adult Attachment Support To Emotion Regulation When Marital Conflicts Happen To Married Women
}

\author{
Sitti Murdiana \\ Psychology Faculty, Universitas Negeri Makassar \\ sittimurdiana@gmail.com
}

\begin{abstract}
This study aims to determine the effect of adult attachment to emotional regulation when facing marital conflicts that happen to married women. The study involved 200 married women who were in the early adult age in Makassar. The subjects of the study were chosen by using non-random sampling technique of accidental type, where the population selected is easily accessible to the researcher, and the available subjects simply became the subjects of the study without any attempt at randomization. The data were collected using adult attachment questionnaire and emotional regulation questionnaire. The data were processed using IBM SPSS statistic version 22, while to analyze how the influence of adult attachment to emotion regulation is done using linear regression. The results of this study indicate the negative influence of attachment anxiety to emotional regulation. The higher attachment of anxiety, the lower ability of emotional regulation is shown by married women and the lower attachment of anxiety of the married women, the higher the emotional regulation. In addition, the results of attachment avoidance positively affects emotional regulation; the higher the attachment avoidance, the higher emotional regulation is shown by married women when they have marital conflicts with their partners, while the lower the attachment avoidance, the lower emotional regulation is shown.
\end{abstract}

Keywords: Adult attachment, emotional regulation, marital conflict.

\section{INTRODUCTION}

\section{Married Life}

Marriage is a commitment of men and women to unite themselves and accept the role asa wife and husband. After married life, men and women play their respective roles. They coordinate and interact harmoniously in achieving the goals of living together (Duvall, 1977). The bond between husband and wife not only raises new roles for women and men, but also raises new needs, and has the right and obligation to handle those needs. Wives have a need to get the affection and attention from their husbands; the need to secure a sense of the relationship, the need to be understood and the need for intimacy. Similarly, the husbands also have new needs from their wives which are equivalent to the needs of their wives. Husbands and wives also have an obligation to fulfill the needs of their spouses.

In newly married couples, role in their lives simultaneously changes; the emergence of new needs, obligations, and preparing for parenthood. While couples who have entered the mid-life marriage phase (Dominican in James \& Wilson, 2002) also experience turmoil with different dynamics. The problems that arise in marriage are often associated with past experiences of both parties. A research conducted by Simpson, Rholes, Campbell, Wilson \& Tran in Noller \& Feeney (2002) on the transition model enters life as a parent reveals that things that affect marriage life include the environment where married couples live and past experiences of each other.

In addition to past experience, there are many other differences found after marriage, so the marriage often runs not as desired. Some experts agree that conflicts in marriage are inevitable. Conflict is often triggered by differences between wife and husband. According to Miller and Perlman (2009) there are two reasons why conflict is very difficult to avoid in a marriage, the first reason is that everyone has different moods and interests. Couples often have different goals and behaviors that are difficult to avoid. Conflict is also difficult to avoid because of the pressure that occurs in the couple's relationship, causing the emergence of tension at any time.

Previous research has revealed patterns of interaction between couples forming a special bond called adult attachment (Ainsworth, 2004). The parent-child attachment pattern affects the pattern of attachment when one enters marital life (Hazan \& Shaver in Cassidy \& Shaver (2008). This pattern of attachment also affects a person in overcoming conflict with his or her partner. It is revealed by Murdiana (2015) that adult attachment and emotional regulation contribute to resolve marital conflicts. A research conducted by Mason (2004) revealed a pattern of relationship between adult attachments with emotional regulation in married couples.

\section{ADULT ATTACHMENT}

Formed adult attachment begins with an affair between adults and other adults (Bowlby, 1971). Establishing a relationship will form attachment patterns, depending on how long the couple is in a relationship. In adult relationship as well as in child and parent relationship, the presence or absence of attachment components is highly dependent on the degree to which a relationship develops. In adult attachment bonds there is a quality of bonding that includes three factors; 1) the individual will seek contact with the attachment figure when under stress, 2) anxiety will decrease and comfort will increase with the presence of attachment figure. 3) separation and loss of contact with the attachment figure make discomfort (Weiss, 1982; in Lankler Page 14, 2005).

According to Bowlby, the bond that exists with a partner is a relationship in which the couple receives 
and gives attention that is a characteristic of adult attachment. Furthermore, normatively there is a development between parental attachment/parenting, and the reproductive/sexual system into a single unit (Ainsworth, 1990; Bowlby, 1969/1982; Hazan \& Shaver, 1994; Shaver, Hazan, \& Bradshaw, 1988 in Cassidy \& Shaver, 2008). Hazan and Shaver in Cassidy \& Shaver (2008) revealed that a romantic relationship must be established for at least 2 years to form a fully attached bond. A person is involved in a romantic relationship for 2 years and makes her partner meet the needs of attachment, while someone who has a short romantic relationship or does not have a partner tends to keep the parents as a source of fulfillment of needs attachment. In adult bond attachment, the most important relationship is caregiving and sexual system (Ainsworth, Bowlby, Hazan \& Shaver, Shaver, Hazan \& Bradshaw, in Cassidy \& Shaver, 2008).

In this study, the researcher will refer to adult attachment theory proposed by Mary D. Salter Ainsworth in Crowell \& Treboux (2001) on two dimensions of adult attachment that is anxiety and avoidance. The first dimension is anxiety that reflects a person's level of concern about rejection, being abandoned, and unloved by someone who is considered an important figure. The second dimension is the avoidance that reflects one's limitations in establishing intimacy and interdependence with others.

\section{Adult Attachment and Emotion Regulation}

This study discusses the relationship between adult adherence and emotional regulation. In attachment theory, emotions occupy the main place, because intense emotion occurs during the formation of attachment, maintenance, or interference in attachment relationships, and when the attachment relationship is re-established (Bowlby in Hazan, GurYaish \& Campa, 2004). Hazan, Gur-Yaish \& Campa (2004) also affirm that the emotional process that occurs is also an affective regulation that occupies an important part in adult attachment.

The theory of attachment aims to include also cognitive, affective, and behavioral styles that evoke or suppress in general the activity and emotional expression (Cassidy \& Kobak, 1988; Main, 1990; Shaver \& Makulincer, 2002 in Gross, 2007). This strategy refers to the emotional regulation and form of judgment, feelings and trends of one's behavior. Emotion is an experience expressed through cognitive changes that are very easy to occur mentally, behavioral trends and subjective feelings (Oatley \& Jenkins in Shaver \& Maculincer, 2007). Emotional expression is influenced by regulatory efforts which can change, increase, or suppress judgment, attention, behavioral tendencies and subjective feelings.

Shaver (1987) and Oatley \& Jenkins (1996) in Shaver (2007) suggest that emotions are generally influenced by the acceptance of changes in the environment, especially unexpected, surprising, or relevant personal changes. These changes often occur automatically and unconsciously in assessing individual needs, goals, wants, and concerns. But these unconscious changesmust be in a conscious response so that unexpected emotional reactions do not appear.

Shaver \& Mikulincer (2007) revealed that secure attachment facilitates emotional regulatory strategies which aim to reduce tension, maintain comfort, support intimacy relationships and enhance constructive, flexible and adaptable adjustments to reality. Individuals who have a secure attachment can overcome their tension without fear of losing control. For someone who has a willingness and responsive attachment figure, negative emotional expression often reduces the tension intervened by the attachment figure (Shaver \& Mikulincer, 2007). Shaver \& Mikulincer (2007) also add that individuals with good attachment figures learn that tension can be expressed politely without risking their relationship. This increases the balance between experience and emotional expression wisely without hostility, resentment or anxiety about loss of control or loss of relationship.

Adult attachment and emotional regulation are two things that cannot be separated from a process of individuals' relationship withtheir partners. The pattern of attachment that is formed within a certain period of time during marriage affects how a person behaves toward his or her partner so that when problems occur or differences provoke the emergence of an emotional reaction from a person, then the behavior shown refers to the pattern of relationship that exists between a person and his or her partner. Thus, emerging emotional reactions tend to be controlled according to how a person perceives, feels the relationships and patternsthe relationships with his or her partner.

Hypothesis testing this research is based on two research questions; a) is there an effect of anxiety attachment to emotional regulation? b) is there any effect of avoidance attachment to emotional regulation?

\section{RESEARCH METHODS}

Procedure

The research subjects were chosen using non random sampling technique with accidental type. In the selection of research subjects, the researcher met the subjects that have similar characteristics with the research characteristics by chance. Furthermore, the researcher requested the willingness of the subjects which is stated in the letter of approval of the data and taken and signed by the subjects. The data were collected by spreading questionnaires in several places, among others in school (at the time before school which allowed the subjects to complete the questionnaire before their children left), office, at breaks, in some acquaintances and some subjects' houses.

\section{Sample}

This study was conducted on 200 married women with the characteristics; (Mean: 34.74, SD, 5.6), women whose marriage age more than 2 years (Mean, 8.14, elementary, 4.25) and reside in Makassar City. 
Based on the adult age, the subjects who were in early adulthood consisted of $81.5 \%$ and those in adult age were about $18.5 \%$. This suggests that the subjects of this research were generally in the early adult age range. The percentage of marriage age indicates; the first 5 -year marriage age range is about $7 \%$, and the 6 20 year marriage age is about $93 \%$.

\section{Measurement}

The data were collected using two questionnaires namely adult attachment questionnaires adapted from a questionnaire compiled by Kim Bartholomew (2001) and an emotional regulatory questionnaire that refers to the theory of emotional regulation proposed by Thompson (2007).

An adult attachment questionnaire consists of 35 items that have passed validity test and item reliability. Adult attachment questionnaires have a Chronbach alpha value of 0.872 . The subjects who answered very suitable with the favorable item were given a maximum score of 4 and the unacceptable answer was given a score of 1. Meanwhile, for unfavorable items they were given a maximum score of 4 on a very unsuitable answer and scored 1 on a very suitable answer.

The emotional regulation questionnaire consists of 14 items that have passed validity test and item reliability. The emotional regulation questionnaire has a Chronbach alpha value of 0.848 . The subjects who responded very suitable to the favorable item were given a maximum score of 4 and a very unsuitable answer was given a score of 1 , whereas for unfavorable items, they were given a maximum score of 4 on a very unsuitable answer and given a score of 1 on a very suitable answer.

The data collected was obtained using IBM SPSS version 22 and analyzed using multiple linear regression. This analysis aims to see how much influence the attachment of anxiety and attachment to avoid the regulation of emotions in women when experiencing conflicts with their partners.

\section{RESULTS}

The data obtained show that the numbers of married women who are in the range of early adult age and middle age, as well as marriage age,are as the following diagram:

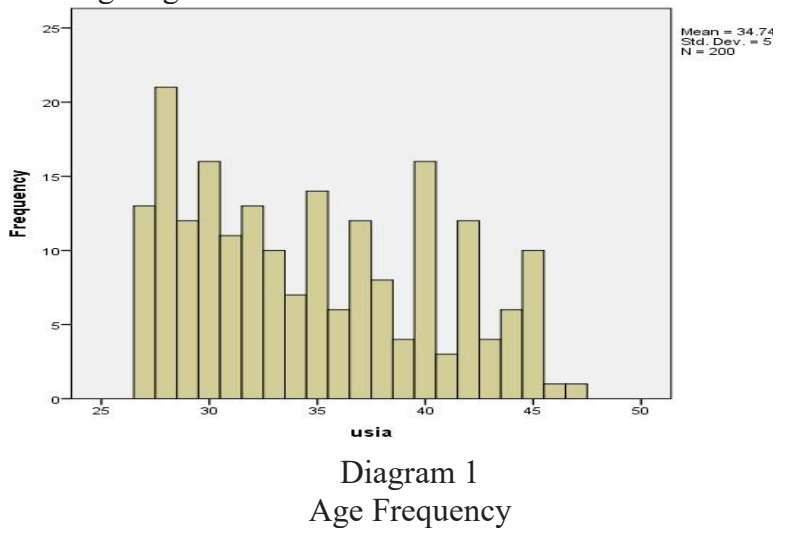

Age Frequency
The subjects in this study consisted of $81.5 \%$ of married women who were in the early adult age range, while $18.5 \%$ were in the middle age range. Women who are in the early adult range by Santrock (1995) and Berk (2010) are divided into three stages: early adulthood, middle adulthood and late adulthood. The subjects in this study are generally positioned in the early adult age range at the age of 18 to 40 years (Berk, 2010). Married women in the adult age range consisted of $18.5 \%$. This middle adult range starts from the age of 40 years and ends at the age of about 65 years. This period is marked by the increasingly narrow choice of life and the future as children leave home and career paths begin to cut off (Berk, 2010). Erickson describes this period as a period of generativity versus stagnation. Generativity involves reaching out to others by giving and guiding the next generation.

The percentage of marriage age in this study is described by the following diagram:

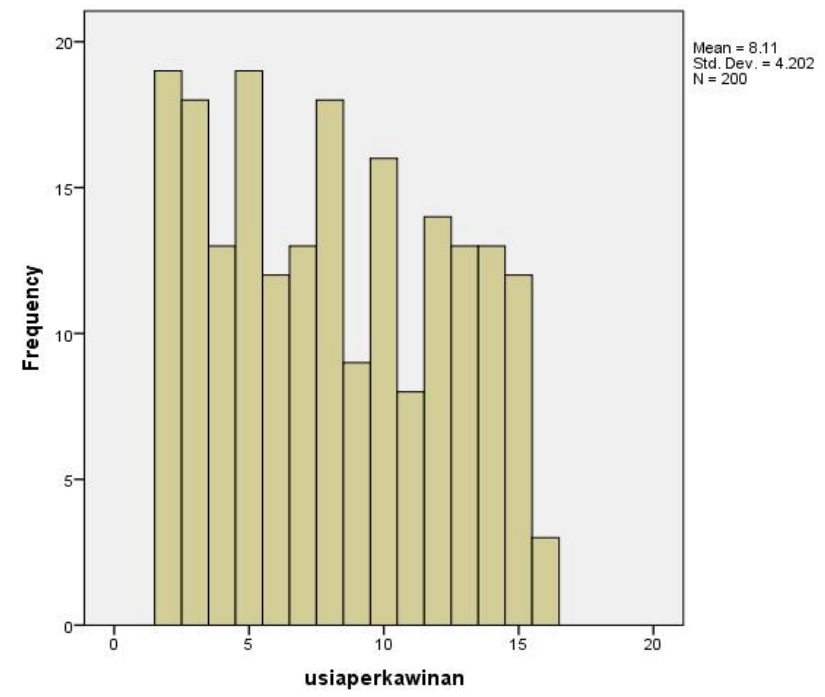

Diagram 2

Marital age

The marriage age in this study showed that the first stage of marriage consisted of $7 \%$ and the middle age of marriage of $93 \%$. In the first year of marriage, Dominian in James \& Wilson (2002) emphasizes the physical conditions associated with sexual adjustment. Thornes and Collard in James \& Wilson (2002) found that 10 to 20 percent of couples experience dissatisfaction with the fear of pregnancy, possibly also the difficulty of combining romance and physical relationships (James \& Wilson, 2002). Emotional tasks and the ability to adapt to physical closeness and emotional closeness are also the keys. In this study, married women are generally in the mid-marriage stage. This stage is usually associated with the decrease in marital satisfaction, due to the business of wife and husband (Dominian in James \& Wilson, 2002).

Before answering research questions, the three variables in this study, the effect of attachment of anxiety and attachment to avoid the regulation of emotion has been tested normality. The result of 
normality test from this variable shows that the three variables are normally distributed. The anxiety attachment variable shows Asymp's results. Sig (2tailed) are: 0.056 , attachment avoidance variable: 0.053 , and emotion regulation variable: 0.20 , greater than 0.05 , so it can be said that the above three variables are normally distributed.

Furthermore, it is also shown multiple linear regression test with significance value of $<0.05$ on the influence of anxiety attachment variable \& avoidance attachment to regulation of emotion. The result shows the correlation between variables as follows:

Table 1

Model Summary

\begin{tabular}{|l|l|l|l|l|}
\hline Model & $\mathrm{R}$ & R Square & $\begin{array}{l}\text { Adjusted R } \\
\text { Square }\end{array}$ & $\begin{array}{l}\text { Std. Error of } \\
\text { the Estimate }\end{array}$ \\
\hline 1 & $160^{\mathrm{a}}$ & .026 & .021 & 6.12533 \\
\hline
\end{tabular}

Value of $\mathrm{R}$ (correlation coefficient) and $\mathrm{R}$ square (coefficient of determination) shows that the contribution of influence of anxiety attachment to emotional regulation is $2.6 \%$, while the rest $(97.4 \%)$ is influenced by other factors.

When looking at the test results of the avoidance attachment variable to emotional regulation, it looks a little bit different. It can be seen in table 3 below:

Table 2

\begin{tabular}{|c|c|c|c|c|}
\hline & lodel Su & Immary & & \\
\hline Model & $\mathrm{R}$ & $\begin{array}{c}\mathrm{R} \\
\text { Square }\end{array}$ & $\begin{array}{l}\text { Adjusted } \\
\text { R Square }\end{array}$ & $\begin{array}{l}\text { Std. Error of the } \\
\text { Estimate }\end{array}$ \\
\hline 1 & $.253^{\mathrm{a}}$ & .064 & .060 & 6.00247 \\
\hline
\end{tabular}

The value of $\mathrm{R}$ (correlation coefficient) and $\mathrm{R}$ square (coefficient of determination) shows that the contribution of avoidance attachment to emotional regulation is $6.4 \%$, while the rest $(93.6 \%)$ is influenced by other factors.

\section{CONCLUSION}

The results of the study of 200 married women led to several conclusions. It reveals the existence of two groups of adults, early adulthood and middle adulthood. Meanwhile, the subjects of this studyare more dominated by married women who are in the early adult age range. Besides, the age of marriage is more dominated by the middle age of marriage. The results of the analysis showed the positive and significant effect of the two independent variables, namely the anxiety attachment and avoidance of attachment to regulation of emotion as a dependent variable. The higher the anxiety attachment and avoidance attachment, the higher emotional regulation of married women when they are in conflicts with their partner.

\section{REFERENCES}

Ainsworth, Mary D. Salter. (2004) Attachment and Other Affectional Bonds Across the Life Cycle dalam Parker, Hinde, \& Marris; Attachment Across the Life Cycle. London. Routledge.

Bartholomew, Kim. Henderson, Antonia. \& Dutton, Donald. 2001. Insecure Attachment and Abusive Intimate Relationship. In Christopher Clulow. Adult Attachment and Couple Psychotherapy. London. Brunner-Routledge.

Bermundez, Maria Judith. 2002. Conflict Resolution Among Latino Couple. Dissertation.Virginia. Virginia Polytechnic Institute and State University.

Bowlby, John. (1969). Attachment and Loss; Volume 1 : Attachment. London. The Hogart Press. (1971). Attachmentand Loss; Volume II; Separation, Anxiety and Anger. London. The Hogart Press. (1980). Attachmentand Loss; Volume III; London. The Hogart Press.

Cassidy, Jude and Shaver, R. Phillip. 2008. Handbook of Attachment ; Theory, research, and clinical application. Second edition. New York. The Guilford Press.

Crowell \& Treboux . 2001. Attachment Security in Adult Partnerships dalam Adult Attachment and Couple Psychotherapy (edited by Christhoper Clulow). London. Brunner-Routledge.

Feeney, Judith A. 2008. Adult Romantic Attachment dalam Cassidy \& Shaver (Editor), Handbook of Attachment. New York. The Guilford Press.

Gross, James J., \& John, Oliver P. 2007. Individual Differences in Emotion Regulation dalam Handbook of Emotional Regulation. New York. The Guilford Press.

Gross, James,J. 2007. Handbook of Emotional Regulation. New York. The Guilford Press.

Hazan, Cindy., Campa, Mary., \& Gur-Yaish, Nurit. 2006. What Is Adult Attachment. dalam Mikulincer \& Goodman (Editor), Dynamic of Romantic Love. London. The Guilford Press.

James, Adrian L, \& Wilson, Kate. 2002. Couple, Conflict, and Change: social work. London. The Taylor \& France e-Library.

Lankler, S.Jill. 2005. Adult Attachment Styles and Relationship Themes; Is there an empirical link. Dissertation. Institute of Advanced Psychological Studies. Adelphi University

Mason, T.L. 2004. The Relationship Between Adult Attachment Security and Emotion Regulation Strategies. Dissertation. Virginia. George Mason University

Mikulincer, M., \& Goodman, S. Gail. 2006. Dynamic of Romantic Love; Attachment, Caregiving and Sex.. New York. The Guilford Press

Mikulincer, M., dan Shaver, R.P. 2004. Security-Based SelfRepresentations in Adulthood; Content and Process; dalam Rholes dan Simpson (Editor). Adult Attachment. New York. The Guilford Press.

Mikulincer, M., dan Shaver, R.P. 2004. What Do SelfReport Attachment Measure Assess?; dalam Rholes dan Simpson (Editor). Adult Attachment.New York. The Guilford Press

Mikulincer, M., dan Shaver, R.P. 2008. Adult Attachment and Affect Regulation dalam Cassidy dan Shaver (Editor). Handbook of Attachment. New York. The Guilford Press.

Miller, Rowland S. \& Perlman, Daniel. 2009. Intimate relationship.Fifth Edition. New York. McGraw Hill.

Murdiana, Sitti. 2015. Pengaruh Trait, Kelekatan Dewasa, Regulasi Emosi terhadap Penyelesaian Konflik 
Perkawinan; Disertasi. Bandung. Universitas Padjadjaran.

Noller, Patricia \& Feeney, Judith A. 2002. Understanding Marriage. Cambridge. Cambridge University Press.

Thompson, Ross A. \& Meyer, Sara. 2007. Socialization of Emotion Regulation in the Family; dalam James J. Gross (Editor),Handbook of Emotion Regulation.New York. The Guilford Press.

Shaver, R. P dan Mikulincer, M. (2007). Adult Attachment Strategies and the Regulation of Emotion dalam James J. Gross (Editor),Handbook of Emotion Regulation.New York. The Guilford Press. 